optically active constituents by fractional crystallisation of the alkyl strychnine phthalates, R.O.CO. $\mathrm{C}_{6} \mathrm{H}_{4}$.CO.O.X, or similar salts, in which $R$ is the alcohol radical and $X$ is a suitable alkaloid; of these fourteen alcohols, only one had previously been obtained in an optically active form.

The labour involved in resolving so long a series of compounds can scarcely be appreciated except by those who have taken part in similar investigations, but in the present case the effort has been well rewarded by the production of material of unrivalled value for elucidating all the various problems involved in the study of optical rotatory power. The complete series of alcohols from $\mathrm{CH}_{3}$. $\mathrm{CHOH} . \mathrm{C}_{2} \mathrm{H}_{5}$ to $\mathrm{CH}_{3}$. $\mathrm{CHOH} . \mathrm{C}_{11} \mathrm{H}_{23}$ shows a perfectly regular gradation of properties, except in the case of the initial member, which shows an exceptionally large decrease of rotatory power with rise of temperature.

As illustrating the extreme sensitiveness of rotatory power to small changes of conditions, it may be noticed that ethylhexylcarbinol, $\mathrm{C}_{2} \mathrm{H}_{5} . \mathrm{CHOH} . \mathrm{C}_{6} \mathrm{H}_{2}$, in complete contrast to methylhexylcarbinol, $\mathrm{CH}_{3}$. CHOH. $\mathrm{C}_{6} \mathrm{H}_{13}$, or the methylheptylcarbinol, $\mathrm{CH}_{3}$. CHOH. $\mathrm{C}_{7} \mathrm{H}_{15}$, with which it is isomeric, has a positive instead of a negative temperature coefficient, the rotatory powers of the isomeric alcohols being equal at $76^{\circ}$, but diverging when the temperature is raised or lowered. An even more drastic change of properties is observed on passing from phenylethylcarbinol, $\mathrm{C}_{6} \mathrm{H}_{x} . \mathrm{CHOH} . \mathrm{C}_{2} \mathrm{H}_{5}$, to phenylmethylcarbinol, $\mathrm{C}_{6} \mathrm{H}_{3} \cdot \mathrm{CHOH} . \mathrm{CH}_{3}$, or from methylbutylcarbinol,

$$
\mathrm{CH}_{3} \text {. } \mathrm{CHOH} . \mathrm{C}_{4} \mathrm{H}_{9} \text {, }
$$

to the isomeric methylisobutylcarbinol,

$$
\mathrm{CH}_{3} \text {. } \mathrm{CHOH} . \mathrm{CH}_{2} \cdot \mathrm{CH}\left(\mathrm{CH}_{3}\right)_{2} \text {, }
$$

whereby the rotatory power is almost doubled in each case.

\section{THE TEACHING OF SCIENCE IN SECONDARY SCHOOLS.}

THE following notes on the subject of science teaching in grant-earning secondary schools in England are based on the reports and observations of certain of the Board's inspectors, who were instructed to pay special attention to this matter during the past year. While an attempt will be made to note the principal changes that have occurred in recent years, to point out certain directions in which improvements have taken place, and to direct attention to some existing defects, the time has not yet come when a detailed and systematic survey of the state of scientific instruction in English secondary schools could profitably be undertaken. Since 1902, when the schools of science or "organised science schools" of the Science and Art Directory became the Division A Schools of the Regulations of that year, the number of secondary schools recognised for grant has risen from 348 to its present figure, 84r. The earlier portion of this period was one which saw a gradual transformation from curricula which were predominantly scientific and mathematical to curricula in which a more even balance of studies was secured; and the whole period of growth and transition has been characterised (quite apart from the effect of alterations in the Board's Regulations) by notable changes in the methods, and to some extent also in the aims, of science teaching.

\section{Changes in the Board's Regulations.}

A comparison of the Regulations which in 1902 applied to the 221 schools in Division A (consisting in about equal proportions of municipal schools and higher grade board schools on one hand and schools of the endowed-school type on the other) with the Regulations now in force will show the magnitude of the change which has been brought about in the conditions under which the teaching of science in this section of the grant-earning schools is carried on. Thus in 1902 not fewer than thirteen hours a week were assigned to the obligatory subjects-mathematics, physics, chemistry, drawing, and practical geometry-of which not more than five hours might be assigned to mathematics. Even in the 127 schools belonging to the "Division B" of the Regulations of 1902, nine 1 From the Report of the Board of Education for the year 19o9-10 London: Wyman and Sons; Ltd.). Cd. 56 r6. Price $8 d$.

NO. 2 I66, VOL. 86$]$ hours a week, or alternately a third of the total number of hours of instruction, were assigned to mathematics and science, of which four hours, or alternatively half the required minimum for both subjects, were allotted to science. Moreover, the Board not only determined the time which was to be allotted to science in each year of the "course," but indicated the syllabus to be followed in the various subjects of the "advanced courses" taken by the "Division A" schools. At the present time the Board's Regulations impose no conditions as to the syllabus of work to be followed and make no specific requirements as to the time to be assigned to the different subjects of the curriculum. Side by side with the increased freedom which has been given to the schools there has, as a fact, been a considerable reduction in the amount of time allotted to science in schools of the "Division A" type and to some degree also in schools of the "Division $B$ " type. In schools of the former class the time given has commonly been reduced from some seven or eight hours a week to four or five in the upper forms, while in the lower forms the proportionate reduction has been greater. This has entailed considerable modification in the syllabus of work and, in general, a lowering of the possible standard of attainment.

\section{Subjects Studied.}

In practically all boys' schools the subjects taken are chemistry and physics, while in the majority of girls' schools botany is the main science subject, a minority taking either physics or more often chemistry. It is usual both in boys' and in girls' schools to find the study of one or other of these subjects preceded by a course of "experimental science" in which the formal separation into chemistry and physics is deliberately avoided. A considerable number of girls' schools, however, still exist in which botany is the only subject taken, or in which the attempt is made to teach botany concurrently with "experimental science"-a plan which, owing to the limited amount of time available, is rarely found to work well.

Hygiene, taught as a science subject, finds a place in the courses of a relatively small number of gírls' schools and of a certain number of mixed schools, the subject being taken by the girls only. The inclusion of hygiene in the course is, as a rule, justified primarily on ethical grounds, i.e. with a view to the inculcation of hygienic habits. It is perhaps scarcely necessary to observe that there are wide differences of opinion as to the extent to which it is necessary or practicable to give this ethical teaching a formal scientific basis. The number of schools in which other science subjects, e.g. geology, astronomy, and zoology, are taught is exceedingly small, though there is some incidental teaching of the two former subjects in connection with the work in geography, while zoology very occasionally appears, and then for examination purposes, in the courses taken in the upper forms. Naturestudy, a conveniently elastic term which covers work of the most various kinds, is ordinarily included among the subjects taught in the junior departments of both boys' and girls' schools. The subject is best taught when it is in the hands of a teacher (not necessarily the teacher of science) who is an enthusiast on natural history. In too many girls' schools in which botany is the main science subject the mistake is made of limiting the work to a preliminary study of plant life supplemented, it may be, by the making of weather records. In a few schools the plan of closely associating the early work in geography with nature-study has been tried with encouraging results.

\section{Courses of Work.}

(a) The differences which exist, and still more perhaps the differences which ought to exist, between the curricula of different grant-earning secondary schools make it practically impossible to comment in general terms on the character of the science work attempted and the standard reached in the several subjects taken. The probable aftercareers of the pupils, the facilities for teaching individual subjects offered by the school and its environment, and the time which it is found possible to devote to science teaching are determining factors on which the choice of sub- 
jects, the range of the work, and the possible standard of attainment will necessarily depend. A course which is suitable in one school may be quite unsuitable in another. In those schools from which a certain number of the pupils pass on to university work in science, and in which a fair proportion remain until seventeen and over, or in which the course is definitely specialised (e.g. schools with a "rural bias"), the problem of the science syllabus tends indeed to solve itself; but in the large number of schools in which school life ends not later than sixteen, this is not so. If in these schools the best possible use is to be made of the time available, it is plainily desirable that the syllabus should represent something more than the initial stages of a study which the pupils will never continuethat it should have, in fact, a purpose and completeness of its own. Again, on the general principle that the curriculum of a school should be narrowed at the top, it should follow that in a certain proportion of schools the allowance of time would be such as to enable boys of sixteen or seventeen to attain a standard in more than one science subject over and above the limited standard required for "school leaving" or " matriculation" examinations. In schools of this type it may well be the function of the science teachers to save the curriculum from the dangers of an all-round mediocrity. This will apply more particularly to urban schools from which a considerable number of pupils pass on to scientific or quasi-scientific occupations.

(b) But whatever the circumstances of the school, no treatment of the science work can ever be satisfactory which leaves wholly out of consideration the relations of science to other subjects in the curriculum. Mathematics is an obvious case in point. The adoption of the same reclassification of the pupils for both mathematics and science is a plan for which there is very much to be said; but in the smaller schools there are practical difficulties in the way, which account for the fact that this expedient is rarely adopted. On the other hand, it is much to be wished that a certain proportion of teachers should be encouraged to qualify themselves to take both these subjects, and, questions of organisation apart, that teachers of physics and mathematics should always work in close touch with one another. In this connection a special point (which has received frequent notice in inspection reports for several years past) may be mentioned. It is very desirable that mensuration, which in a considerable number of schools is still included in the science course, should be transferred to its proper place in connection with the teaching of arithmetic to boys and girls in the junior departments. If this were done it would be possible, and often advantageous, to amplify the course in practical physics by the introduction, at some stage in the course, of experimental work in elementary mechanics, a subject which at the present time is too often neglected in schools. In addition to mathematics, geography, advanced manual instruction, and domestic economy may all contribute elements of value to the teaching of science, and be in turn assisted by it. It is necessary, however, to add the warning that the teacher who endeavours to teach two subjects in one may succeed admirably in teaching neither.

(c) The detailed syllabuses in particular subjects show in many cases curious, if not inexplicable, limitations. There is, for example, a tendency to refrain from all mention of scientific matters of common interest, because they do not admit in school work of complete and exhaustive treatment. Electricity and magnetism (including magnetic measurements) form part of the work in many boys' schools, but the motor and the dynamo are not even mentioned, because time does not permit of the study of electromagnetism. Every child is interested in soap bubbles, but the maiority of bovs and girls are not introduced to the simplest consideration of the phenomena connected with surface tension. There is no subiect more generally studied than heat, but if a boy leaves school with any knowledge of how a locomotive works it will usually be the result of his own unaided researches. It is certainly unfortunate that pupils who learn science should be sent out into the world wholly ignorant of matters in which they are naturally disposed to be interested. Svllabuses of work, admirable for the purpose of instilling NO. 2 I66, VOL. 86$]$ scientific method, may and sometimes do err in the direction of being inhuman.

(d) In the same way, it is important that in the actual teaching every opportunity should be taken of illustrating facts and principles learnt in the laboratory by frequent reference to everyday phenomena. This is a matter which requires the most careful attention in boys' schools no less than in girls' schools, in physics no less than in chemistry. Appropriate illustrations give a reality to the work which it sometimes lacks. They should, of course, be introduced as illustrations, that is to say, when, and only when, they may happen to be wanted to give point to the teaching. They are useful just in so far as they serve this purpose, and just in so far as it is remembered that the teaching is concerned with science and scientific method, and only in a secondary sense with its application to industry and the arts.

(e) Again, it is probably neither possible nor desirable to add to the number of science subjects which the pupils will systematically study in the laboratory and the classroom. There is the more reason why they should be encouraged to interest themselves in some aspects of nature other than those to which attention is given in school hours. For this the "school scientific society" may offer the needed opportunity by providing for the older pupils the occasion of taking up subjects for themselves and sharing their interests with their fellows.

\section{Equipment.}

In the matter of laboratory accommodation and equipment it is satisfactory to note that local authorities and governing bodies of endowed schools have commonly shown a generous appreciation of the requirements of science teaching. It is comparatively rare to find, except perhaps in connection with the teaching of botany, that the work is seriously handicapped by deficiencies in equipment, and the occasional suggestions of inspectors under this heading are directed, as a rule, to securing a suitable adaptation of the arrangements of the older laboratories to modern requirements. These will naturally vary in different schools with the character and extent of the course of work attempted, and it is for this reason desirable that the authorities concerned in the planning of new or the alteration of existing laboratories should take every opportunity of effectively consulting the responsible teachers. It is sometimes forgotten that space is more valuable than elaborate fittings, and that suitable provision for upkeep and apparatus is essential to the proper conduct of a laboratory. Economy and efficiency alike demand that a laboratory should not be regarded as something ready-made which can be ordered once for all from a manufacturer. On the contrary, when the essentials have been provided, a laboratory, like a library, should be allowed to grow.

\section{Influence of Examinations.}

Any consideration of the present state of science teaching would be obviously incomplete if it avoided all reference to the effects of examinations. In this connection, then, it is satisfactory to observe that the work of the schools, at any rate in the lower and middle forms, is far less determined by examination requirements than was the case even a few years ago, and that there is an increasing tendency among teachers to be guided in their teaching by strictly educational aims. At the same time there has been a marked improvement in the character of the syllabuses of certain examinations commonly taken, and a consequent improvement in the character of the work attempted in many of the schools. Notwithstanding this, it has to be recognised that a detailed syllabus put forward by an examining body, however unexceptional the syllabus may be, has its inevitable disadvantages: for it is only too likely that when a teacher has such a syllabus before him, his teaching will follow a predetermined line, whereas in connection with the teaching of science it is especially desirable, not only that the teacher should, within limits, make his own syllabus, but that he should feel free at any moment to depart from it. An examina- 
tion may be unsuitable in a particular school either because the syllabus is so restricted that the last year's work tends to be a mere repetition (sometimes with a minimum of practical work) of what has gone before, or because the syllabus in a particular subject-chemistry, for examplecovers so wide a field that the teachers in the limited time available practically confine themselves to this subject alone, and in dealing with it are forced back on mere bookwork and informational teaching

Relation of Theoretical to Practical Teaching.

Attention has been frequently directed in the reports of inspectors to the necessity of establishing a right relation between the theoretical and practical teaching of science. $\mathrm{By}$ this is meant, not only that the two modes of treatment should be closely associated with one another, but that they should be placed in their right order. In this important matter there has been a notable improvement in the methods of teaching followed in the schools, and criticism in this region is likely in the future to be more concerned with details than with matters of principle. Though opinions differ as to the precise methods by which the desired results are to be secured, it is now very widely recognised that the teaching of a class should, so far as possible, be based on the practical work done by the members of the class. As a fact, lectures have largely given place in elementary teaching to class discussions on the practical work assisted by occasional demonstrations, and the change has been beneficial to the work of the lower and middle forms. In some cases, however (as will be pointed out later on), the practical work has not been supplemented by any adequate discussion of its results. In other cases, the reaction against formal lectures has gone so far as to lead teachers to rely exclusively on the experiments carried out by the class. There is reason to think that when this is done the teaching loses in effectiveness.

Practical work in the lower and middle forms ordinarily follows on a brief discussion of the matter to be investigated, and a written account of the experiment to be carried out is regularly required. Such written accounts should, of course, be the outcome of the pupil's own efforts, and not be, to all intents and purposes, dictated br the teacher or copied from a book. So far as these records are concerned, there has been of late considerable improvement. The mechanical entering up of results in spaces set apart for the purpose, or the filling up of columns under the headings " experiment," "observation," "inference," has nearly disappeared; but more remains to be done in regard both to the form and substance of the record. The idea that there are two standards of composition, one which is appropriate for the English lesson, and another which is good enough for the science laboratory, has not yet been eradicated. But, apart from this, the notebooks often include accounts which are satisfactory in so far as they are purely descriptive, but which fail to show how the "conclusion" follows from the observations recorded or to state what assumptions have been made in the argument. It is not, indeed, uncommon to find conclusions recorded which the pupil's own work quite fails to justify. The "doing", is, in fact, unaccompanied by any honest thinking about what has been done. There is, of course, nothing in this to cause surprise. To expect exactness of thought and accuracy of expression from younger pupils is to expect the ripe fruits of scientific education from those who have but lately begun to enjoy its benefits. If these logical errors never occurred, there would be no need to spend time over teaching " scientific method." It is precisely by seizing the opportunities which such mistakes and omissions afford that the teacher can convey to the pupil valuable lessons in the logic of science.

So far as the actual experimental work is concerned, its value depends in different schools on the extent to which the pupil is encouraged to use his own eves, to apply his powers of reasoning to the problem under consideration, and to criticise his own procedure. The work should, in fact, serve not only to develop the powers of observation and reasoning, but to inculcate " an increasing respect for precision of statement and for that form of veracity which consists in the acknowledgment of difficulties." It is quite NO. 2 I66, VOL. 86$]$ possible for pupils to work through a sei of disconnected experiments and to get little out of it beyond a certain facility in easy manipulation. Work of this kind may be as mechanical and as far removed from being really practical as anything that is done in a classroom. The necessities of the school time-table often lead to the work being broken up into the performance of a series of isolated experiments, one for each lesson period. There is, therefore, the more reason why teachers should be on their guard against the serious danger of making the single experiment the unit of teaching. The exclusion of experiments which are trivial, or of which the results are selfevident, and the occasional adoption of the plan of allowing different groups in a class to work at different though allied experiments, the results obtained by each group being available for the whole class and used in the subsequent discussion, would do much to widen the pupils' experience and give the work a seriousness and importance which it sometimes lacks.

The remarks in the two preceding paragraphs are intended to apply more particularly to the treatment of the practical work in all science subjects in the lower and middle forms. The methods appropriate to the teaching of the higher forms are, in general, much better understood, and need not now be dealt with. But the teaching of botany requires special notice, especially in view of the important position it occupies in the science work of girls' schools.

Teaching of Botany.

Considerable changes have been effected in recent years in the method and scope of botanical teaching. The time given to the purely descriptive work connected with the classification of plants in their natural orders has been greatly curtailed, and it is now common to find included in the course an experimental treatment of plant physiology and some consideration of the question of habitat. There is, too, an increasing tendency to recognise that no adequate study of botany is possible without some knowledge of the elementary facts and principles of chemistry and physics. The broader treatment which the subject now receives, and the substitution of a partially experimental for a purely descriptive method, have led to a healthier development of science teaching in many girls schools. But the new methods have brought with them their own special difficulties, which, in most cases, still await solution. It is rare, for example, to find the experimental work on plant physiology really well done, and the possibilities of the school garden as an adjunct to the laboratory are insufficiently realised by teachers of botany.

Though in connection with this subject it is possible to record a general tendency in the right direction, and in a fair number of instances a real advance, it is still the case that in too many schools botany is regarded somewhat in the light of an accomplishment, making no very serious demands on the pupils' intelligence and requiring little more by way of equipment than a classroom and a bunch of flowers.

In conclusion, it may be stated that if attention has been deliberately directed in some of the foregoing paragraphs to certain existing defects in the teaching of science, this is due to no failure to recognise the excellence of the work which in many secondary schools is being done under the guidance of skilled and experienced teachers.

\section{THE SCIENCE MUSEUM AND THE GEOLOGICAL MUSEUM}

THE report of the Departmental Committee on the Science Museum and the Geological Museum was published a few days ago. The committee was appointed in March, Igro, and its terms of reference were:-"To consider and report upon various questions in regard to the present condition and the future development of the valuable collections comprised in the Board's Science

1 Report of the Departmental Committee on the Science Museum and the Geological Museum. Cd. 562 . (London: Wyman \& Sons, Ltd Price $3 d$. 